CARRASCO \& GARCÍA-HUIDOBRO/ Repensando nuestros posicionamientos como profesoras de arte dentro de un escenario de cambios

\title{
Repensando nuestros posicionamientos como profesoras de arte dentro de un escenario de cambios
}

\author{
Rethinking our positions as art teachers in a changing scene
}

\author{
Sara Victoria CARRASCO. Universidad de Barcelona (España). \\ s_carrasco_s@msn.com \\ Rosario GARCÍA-HUIDOBRO. Universidad de Barcelona (España). \\ rosarioghm@gmail.com
}

Resumen: Este artículo intenta rescatar algunas de las ideas que para nosotras como profesoras de artes visuales son relevantes al momento de afrontar la enseñanza de las artes en la educación chilena actual. Estas ideas emergen de algunas contribuciones obtenidas durante el seminario "Diálogos entre la educación artística y los desafíos del siglo XXI", que se desarrolló en Santiago de Chile durante el año 2014. Este encuentro nos permitió dialogar y reflexionar, a partir de los relatos y experiencias de los(as) académicos(as) que participaron con sus ponencias, en torno a cómo la educación artística se ha visto influenciada por los desafíos sociales, culturales, políticos y económicos que hacen frente a la situación en Chile durante los últimos años. A partir de aquí rescatamos como ejes centrales las nociones de "posmodernidad" y "posicionamiento" para repensar algunos de los desafíos que enfrenta la educación artística y el rol de las y los docentes de arte dentro este cometido.

Concebimos la noción de "posicionamiento" como un elemento que puede adquirir un nuevo sentido desde la postura post-estructuralista y otorgar otro valor a las prácticas educativas artísticas, ya que nos permite cuestionar y reflexionar nuestros propios roles como enseñantes de las artes y algunos de los discursos artísticos que se comparten con los y las estudiantes dentro del proceso educativo. Con ello, proponemos pensar la tarea docente desde una posición fluctuante y en constante movimiento donde no exista una sola manera de ser docentes, ni un único modo de hacer o constituir las relaciones pedagógicas a fin de pensar otros espacios y posibilidades que permitan a los estudiantes a resituarse en el centro de la acción educativa desde la significación de sus propias experiencias. 
Palabras claves: posmodernidad, posicionamiento, enseñanza artística, enfoques artísticos.

\begin{abstract}
This article rescues some ideas that for us, as art teachers, are relevant when facing the art teaching in the current Chilean education. These ideas emerge from some of the contributions share during the seminar "Dialogues between art education and the challenges of the XXI century", developed in July 2014 in Santiago, Chile. This meeting allowed us to dialogue and reflect, based on the stories and experiences of the academics that participated as speakers, how art education has been influenced by the new social, cultural, political and economic challenges which face the current situation in Chile in recent years. From here we rescue the notion of positioning and the postmodern perspective as main elementsto rethink the challenges of art education and the role of teachers in this labor.
\end{abstract}

We conceived the notion of "positioning" as an element that can acquire a new sense from the post-structuralism stance and give another value to the educational practices of arts, allowing us to question and reflect our own roles as art teachers and some of the artistic discourses that are shared with the students in the educational process. Hence, we proposed to think our teaching task from a fluctuating position and constantly moves, where there is not only one way to be teachers, or one way to do or conform pedagogical relationships, with the intention to think others spaces and possibilities that allow students to reposition in the center of educational action from the significance of their own experiences.

Keywords : postmodernism, positioning, art education, artistic teaching approaches.

\title{
Introducción
}

El seminario que da origen a este artículo, titulado "Diálogos entre la educación artística y los desafíos del siglo XXI", se configuró como un espacio de encuentro y conversación con el objetivo de comprender cómo la educación artística se ha visto influenciada por los desafíos culturales, sociales, políticos y económicos que han acontecido en nuestro país durante los últimos años. Este encuentro contó con algunas ponencias que nos permitieron dialogar y reflexionaren torno a los desafíos y territorios que está ocupando la enseñanza artística. De aquí que el objetivo de esta propuesta no se centra en describir y analizar lo expuesto por cada uno de los ponentes, sino en rescatar algunas de las ideas que emergieron desde allí y que nos parecen relevantes para afrontar la enseñanza de las artes y nuestro rol como docentes en la actualidad, ya sea en Chile o dentro de otro contexto social y educativo. Con esta intención, a continuación revelaremos brevemente algunas de las reflexiones que se llevaron a cabo durante dicho encuentro a través de dos presentaciones, específicamente, con el fin de introducir al lector dentro del contexto donde se gestaron algunas de las reflexiones que serán rescatadas más adelante. 
CARRASCO \& GARCÍA-HUIDOBRO/ Repensando nuestros posicionamientos como profesoras de arte dentro de un escenario de cambios

La primera ponencia -titulada, El desplazamiento de la enseñanza tradicional hacia la incertidumbre contemporánea: desafíos en la enseñanza de las Artes Visuales-fue desarrollada por dos académicos de la Universidad Metropolitana de las Ciencias de la Educación, la Dra. Patricia Raquimán ${ }^{1}$ y el Dr. Miguel Zamorano ${ }^{2}$ .Esta ponencia consistió en compartir relatos y recorridos desde sus propias investigaciones y prácticas docentes en torno a la necesidad de buscar nuevos caminos y herramientas para guiar y acompañar los procesos de formación de sus estudiantes dentro de la formación inicial docente universitaria. Para esto, ambos académicos retomaron la noción de "posmodernidad" con la finalidad de dialogar e intentar (re)comprenderlas posibilidades que pueden articularse a partir de ella y de las múltiples significaciones que surgen dentro de la enseñanza artística. A través de su propuesta era posible advertir una intención de de-construir los relatos hegemónicos y estructuralistas que podían estar prevaleciendo en la educación formal y, a su vez, posicionarse desde territorios que permitieran el transitar dentro de una posición de no saber.

Tomando en cuenta las reflexiones de ambos docentes y la incipiente integración de la perspectiva posmoderna dentro del área de la educación artística en nuestro país, nos pareció una postura disruptiva dentro de un contexto educativo tradicional como éste. Por esto, nos parece relevante no solo rescatar la noción de "posmodernidad" sino también el modo en el que fue presentada, es decir, como un desafío para la educación artística chilena con el fin de visibilizar los aportes que este enfoque posibilita a la educación de las artes a través de otros modo de hacer, ver y comprender la realidad y el conocimiento desde y hacia las artes.

Por otro lado, los diálogos y relatos compartidos durante la segunda ponencia -titulada, Posicionarse en la enseñanza de las artes visuales: enfoques y discusionesestuvieron a cargo de una académica de la Universidad Alberto Hurtado, la Dra. Alejandra Orbeta. La presentación de Orbeta $^{3}$ nos llevó a reflexionar sobre los aspectos de nuestra sociedad líquida y efímera (Bauman, 2007), para repensar desde ahí la noción de "posicionamiento". Esta presentación se centró en reflexionar sobre la educación formal como un fenómeno que experimenta grandes conflictos epistemológicos (Orbeta, 2014), producto de una sociedad en tránsito y de las necesidades y demandas del estudiantado y profesorado que la sitúan como un elemento en cuestión. Junto con esto, hizo especial hincapié en el rol de las y

\footnotetext{
1. Académica y coordinadora del área de Didáctica de las Artes Visuales. Encargada de aseguramiento de la calidad del Departamento de Artes Visuales de la Universidad Metropolitana de Ciencias de la Educación. Doctora en Ciencias de la Educación.

2. Académico de Artes Plásticas de la Universidad Metropolitana de Ciencias de la Educación. Doctor en Filosofía con mención en Estética y Teoría de las Artes.

3. Directora de la carrera de Pedagogía en Artes Visuales en la Universidad Alberto Hurtado. Doctora en Ciencias de la Educación.
} 
los docentes como acompañantes del estudiantado durante este recorrido líquido y efímero que acontece en el proceso formativo, preguntándose también, acerca de los diversos posicionamientos que están operando actualmente dentro de la enseñanza de las artes. A partir de los cinco enfoques sobre la enseñanza artística propuestos por Imanol Aguirre (2005) y fundamentados en tres tipos de modelos el Modelo Logocentrista (el arte como saber dentro de un programa logocéntrico), el Modelo Expresionista (el arte como expresión y la educación artística como autoexpresión creativa) y el Modelo Filolingüista (donde la lengua devuelve la mirada al objeto artístico fijándose especificamente en aquellos aspectos que visualmente lo hacen relevante)-, la académica nos invita a reflexionar y a tomar conciencia como docentes sobre los numerosos modelos que podemos encontrar dentro de la educación artística y los posibles posicionamientos que podemos asumir frente a ellos.

Las formas de concebir la enseñanza de las artes propuestas en ambas ponencias, nos plantean otros espacios y papeles dentro de la educación artística como desafíos que nos llevan a transitar por nuestros roles y articular otros modos no hegemónicos de concebir la enseñanza de las artes, nuestro papel como docentes y las relaciones educativas que establecemos con los estudiantes. Se refieren a formas pedagógicas que conciben la enseñanza artística y el saber construido desde lugares fluctuantes, no preestablecidos, ni jerarquizados. Partiendo de aquí, queremos recuperar la noción de "posmodernidad" como un enfoque incipiente dentro de la educación artística chilena que nos ayuda a profundizar, desde sus múltiples derivaciones y tránsitos, la relación entre los diversos desplazamientos y "posicionamientos" que podemos adoptar como docentes frente a la enseñanza artística. Para esto, primeramente, nos detendremos en desarrollar ambas nociones utilizadas como ejes centrales de este trabajo, y luego, presentaremos un apartado que propone nuestros propios posicionamientos -como profesoras de arte- como una reflexión frente a los enfoques propuestos.

\section{La perspectiva posmoderna dentro del área de la educación artística chilena}

Efland et al. (2003) relata la facilidad con que podemos vincular el giro posmoderno con los cambios que ha venido desarrollando la educación artística desde fines del siglo XXI hasta hoy. Esto, porque el proyecto que ha traído consigo la posmodernidad busca revisar críticamente los antiguos postulados de la ilustración, rechazando la idea del conocimiento como algo organizado y jerarquizado que desarrolló la racionalidad tecnocrática del saber para establecer una genealogía que nos permita comprender hasta dónde enseñamos contenidos, prácticas y metodologías artísticas heredadas del pasado. Ante estas ideas podemos establecer que la crisis de la representación, que ha traído consigo la posmodernidad, se hace latente en el ámbito educativo, pues, en primer lugar se desplaza la idea de que las disciplinas son fuentes de enseñanza fiables y universales. Así también se cuestiona 
la universalidad del conocimiento y los elementos que constituyen el currículo. En el ámbito artístico esta crisis pone de manifiesto un rechazo o cuestionamiento de las formas artísticas de enseñanza. Esto ha traído un cambio de paradigma en la educación del arte (Aguirre, 2005; Efland et al., 2003), puesto que si la función del arte se basa en modos de construir la realidad, entonces las finalidades de la educación artística serían, entre muchas otras, la de contribuir a ese panorama permitiendo múltiples comprensiones de las posibilidades sociales en las que vivimos, y que los(as) estudiantes puedan comprender estos mundos sociales y culturales a partir de diversos medios artísticos.

Siguiendo esta línea, la corriente posmoderna en la educación artística sugiere la idea del arte como producción cultural (Efland et al., 2003), donde se puedan incorporar contenidos multiculturales al currículo para sensibilizar a los estudiantes respecto a temas como la opresión, el género, la desigualdad, etcétera, y así iniciarlos en cuestiones morales que promuevan conciencia y posibilidad de transformación desde las artes. Por otro lado, la influencia de la perspectiva posmoderna también propone que la enseñanza artística sea un espacio disponible para los pequeños relatos en lugar de considerar sólo los metarrelatos. Hablamos de un currículo multicultural donde diferentes relatos puedan dar mayor diversidad cultural, pero también, nos referimos a la posibilidad de diversas experiencias artísticas que amplíen la mirada de las artes y su enseñanza (Carrasco y García- Huidobro, 2016a).

Por otro lado, Efland et al. (2003) también señala la importancia de la idea de la deconstrucción como un tema del currículo. Este término, acuñado por el filósofo Jacques Derrida, sugiere el collage y el montaje como unas de las principales formas estéticas del discurso posmoderno ya que nos permite tomar prestadas imágenes y modificarlas para darles un nuevo significado. Desde este punto de vista la enseñanza de las artes posmoderna requiere de docentes que puedan desarrollar en sus estudiantes habilidades de observar, leer, cuestionar, deconstruir y recrear las imágenes, promoviendo en ellos y ellas valores que les permitan hablar de las imágenes desde un lugar subjetivo.

En Chile, este panorama posmoderno lentamente ha tomado espacio a través de las nuevas reformas curriculares que el Ministerio de Educación ha ido desarrollando en el área de educación artística desde inicios del S. XXI. Por ejemplo, la propuesta curricular del 2002 plantea otra mirada acerca de las artes en el contexto de la educación escolar y preescolar en Chile (Benavides y Leiva, 2002). Esta pone fin a la educación artística como la enseñanza del arte en tanto autoexpresión creativa. Esta reforma sigue las ideas de Elliot Eisner (1998) y Alfonso Padilla (2001), las que se sustentan en tres ejes: el cultural (basado en la historia del arte y el conocimiento de las manifestaciones artísticas), el productivo (enfocado en la expresión y la creación) y el crítico, orientado hacia la apreciación del arte. A pesar de este avance podemos decir que estas nuevas bases curriculares seguían potenciando el desarrollo de los lenguajes artísticos desde la capacidad expresiva, 
la apreciación y la sensibilidad estética, aspectos que recuerdan a la reconstrucción disciplinar propuesta por el D.B.A.E. (Educación Artística como Disciplina). Sobre esta reforma se señaló que,

Los actuales programas de Artes Visuales se han elaborado desde el supuesto de que "hacer arte" es mucho más que dibujar y pintar, superando la tradicional relación de "clase de arte = clase de dibujo". La concepción que subyace a la actual propuesta para la educación artística considera a las artes en general como ponderosas herramientas pedagógicas que contribuyen al desarrollo tanto de habilidades de pensamiento, clasificadas actualmente por la psicopedagogía, como "de orden superior", como al desarrollo de otro tipo de habilidades propiamente humanas como el respeto y la valoración del otro y lo otro, la capacidad de reconocerse como persona con identidad tanto individual como cultural, la capacidad de asombro, la capacidad de expresar sentimientos y emociones, la capacidad de disfrutar con la belleza, la capacidad de resolver problemas, la capacidad de pensar y actuar creativamente, la capacidad de percibir de manera focalizada y las capacidades relacionadas con el autoaprendizaje y la construcción del conocimiento, entre otras (Benavides y Leiva, 2002, p. 109).

En el 2011, en medio de las movilizaciones estudiantiles en Chile, se aprueba un decreto que trae un nuevo plan de estudios para la educación artística. En este sentido, si bien en el 2002 veíamos avances con las reformas curriculares artísticas, ahora se genera un retroceso en el plan de estudios, pues se reducen las horas de arte en el currículum escolar del $2^{\circ}$ ciclo de enseñanza básica. Esto, nuevamente señala la precariedad y marginalidad con que se vive la educación artística en nuestro país (Carrasco y García-Huidobro, 2016b). En parte, una de las críticas que ha esto se atribuye (Díaz, 2014), es el escaso vínculo desarrollado entre el Ministerio de Educación y el Consejo Nacional de Cultura y Arte (CNCA). Respecto a este distanciamiento, es importante precisar que la educación artística ha sido fomentada por el CNCA, tanto a través del programa Okupa (ahora Acciona) como desde de diversos proyectos de experiencias artísticas que promueven la capacidad de transformación en diversos establecimientos educacionales del país (CNCA, 2013). Ante este panorama podemos señalar el predominio que ha tenido el CNCA sobre la educación artística en la educación formal y no formal del país, a través de los diversos programas y proyectos que propone, comprometiendo a las artes "como una disciplina más, con un corpus de conocimiento, un lenguaje y un sistema de enseñanza y producción" (CNCA, 2013, p. 17). Los doce programas que se desarrollaron fueron realizados en instituciones de ámbito público, privado y subvencionado, también en el sistema formal y no formal, como experiencias urbanas y rurales. En este sentido, el desarrollo de estos programas son, siguiendo a Efland et al. (2003), un espacio para incorporar micro relatos sobre experiencias artísticas que transitan de modo paralelo al meta relato que propone el currículo de educación artística.

Por último, se vuelve importante señalar que en el marco de la Reforma Educativa, el Ministerio de Educación y el Consejo Nacional de la Cultura y las Artes se 
encuentran trabajando de manera conjunta en un "Plan Nacional de Artes en Educación (2015-2018)", el que tiene como objetivo fortalecer experiencias del aprendizaje artístico a través de diversas líneas de acción. Algunas de estas están vinculadas con dar nuevas miradas al currículo artístico, crear nuevos programas para fortalecer las experiencias artística de la jornada escolar completa, tanto dentro de las escuelas como en sus vínculos con otras organizaciones artísticas. Además, este proyecto propone colaborar en la formación inicial y continua de artistas y docentes en el área, así como en fortalecer escuelas y liceos artísticos. Por último, propone generar vínculos con organizaciones e instituciones vinculadas a las artes y la educación para generar programas colectivos que desarrollen conocimientos colaborativos. Creemos que estos nuevos desafíos, junto a los que señalaron los diversos académicos en el seminario que dio pié a este artículo, señalan un área que se está reconstruyendo, que se está recolocando y buscando un posicionamiento prioritario en la educación de este país.

\section{La noción de posicionamiento ¿Cómo puede adquirir un nuevo sentido y otorgar otro valor a las prácticas educativas artísticas?}

Dentro de la posmodernidad el giro discursivo actuó como un elemento fundamental. Este vuelco o nueva mirada al lenguaje posibilitó el surgimiento de la "teoría del posicionamiento" como perspectiva que buscaba comprender las relaciones entre los discursos y los fenómenos sociales, permitiendo cuestionar las identidades fijas y preestablecidas para dar lugar a la subjetividad. Desde este enfoque el posicionamiento es definido por Davies y Harré (1999) como el proceso discursivo en el cual los individuos se localizan en las conversaciones. Nos hablan de cómo los individuos podemos ir posicionándonos de varias maneras en una conversación, dado que "al estar posicionada de distintas maneras, la misma persona, experimenta y muestra una multiplicidad de identidades" (Davies y Harré, 2007, p. 245). Siguiendo esta mirada, Harré y Van Langenhove (1999), entienden también el posicionamiento como una forma dinámica de los roles sociales. Este entendimiento de la noción de posicionamiento desde el punto de vista inmanentista del lenguaje, explicado detalladamente por Harris (1982), concede toda la autoridad a la teoría lingüística para seleccionar los datos bajo la idea de que éstos son perceptibles de algún modo, es decir, es la propia teoría la que decide qué es relevante y que no. A su vez, para el punto de vista inmanentista, las reglas o convenciones sociales "son formulaciones explícitas del orden normativo inmanente en producciones humanas concretas, tales como conversaciones reales entre individuos" (Davies y Harré, 2007, pp. 242-243).

Estos autores describen el posicionamiento como un elemento que surge de una conversación a modo de discurso oral, un fenómeno conversacional, ofreciendo el concepto "posición" como reemplazo al concepto de "rol" que es considerado como algo más trascendentalista. A partir de aquí, la noción de posicionamiento contribuye al entendimiento de la persona al igual que el concepto de identidad 
que también ha sido largamente tratado. De esta manera, los individuos adoptan y desarrollan ciertos "roles" al posicionarse de varias maneras diferentes dentro de en una misma conversación. "Al estar posicionada de distintas maneras, la misma persona experimenta y muestra una multiplicidad de identidades" (Davies y Harré, 2007, p.245).

Esta noción de posicionamiento se encuentra ligada a la noción de "subjetividad" y de su naturaleza múltiple y fragmentada, así como de la multiplicidad de posiciones que pueden adoptar los sujetos. Desde las perspectivas postestructuralistas esta noción se aleja de una identidad única y fijada del sujeto humanista, de una identidad unitaria (Baxter, 2003), pasando a entenderse como construcciones en constante devenir que dependen de contextos e interacciones específicas dentro de un momento dado. Dentro de las diferentes corrientes postestructuralistas, el feminismo postestructuralista ha ayudado a entender diversas dimensiones sociales, como el concepto de identidad y subjetividad. A partir de aquí, la subjetividad ha sido concebida como una producción discursiva que se da en un proceso continuo y que nos ayuda a entender el sentido de nosotros mismos y la manera de entender nuestra relación con el mundo (Blakhman et al., 2008) a través de determinadas posiciones delimitadas por condiciones culturales y sociales $-\mathrm{y}$ lingüísticas- que operan en momentos determinados.

A partir de aquí, tanto el posicionamiento como la subjetividad serían procesos por el cual las personas se construyen conjuntamente dentro de determinados contextos sociales y culturales, con el fin de encontrar un lugar dentro de ellos, permitiendo una diversidad de posicionamientos e identidades dentro de dichas interacciones discursivas con los demás. Sin embargo, nosotras queremos rescatar dichas nociones para poner el foco también en la práctica del hacer y no sólo el lenguaje y el discurso; específicamente, en la práctica desde y para la enseñanza artística. Los individuos, tanto en las conversaciones como en sus acciones adoptan y desarrollan ciertos roles -como por ejemplo, el rol del profesor(a) como conocedor de verdades absolutas mientras el(la) estudiante escucha y recibe de manera pasiva-. En este sentido, a pesar de que los(as) profesores(as) podamos adoptar un posicionamiento determinado para cierta acción o práctica discursiva dentro de la relación educativa, tal como nos siguieren las perspectiva postestructuralista, no sostenemos una posición única y fija durante todo el transcurso de una conversación, de una acción o de un proceso de enseñanza. Éstos van circulando y cambiando según el posicionamiento epistemológico y ontológico que adoptemos frente a una realidad determinada o frente a los otros (estudiantes, otros profesores, directivos) dentro de un contexto específico (escuela, universidad, centro cultural, vecinal). De aquí que estos diversos modos puedan estar relacionados tanto con el decir como con el ser $y$ hacer de los(as) profesores, por tanto el término posicionamiento nos ayuda para describir las diversas dinámicas que se llevan a cabo también en la práctica docente. Unas dinámicas que se articulan de diferentes modos y que no pueden fijarse, pues están en un constante movimiento, en un constante devenir que produce eventos pedagógicos (Atkinson, 2011; Badiou, 2005). 
CARRASCO \& GARCÍA-HUIDOBRO/ Repensando nuestros posicionamientos como profesoras de arte dentro de un escenario de cambios

A partir de aquí, si consideramos que los(as) profesores desarrollan su práctica desde un conjunto de posiciones y que asumen diversas colocaciones entre las que pueden moverse y transitar, valdría la pena considerar ¿cuáles son los posibles posicionamientos que son asumidos en los diferentes enfoques propuestos dentro de las ponencias y a qué tipo de discursos hacen referencia? Y, por otro lado, ¿cuáles son nuestros propios posicionamientos como profesoras de arte frente a los enfoques propuestos y la enseñanza de las artes?

\section{Repensar nuestros posicionamientos dentro de la enseñanza de las artes desde los enfoques propuestos}

Si retomamos la invitación que nos hizo Alejadra Orbeta sobre "tomar consciencia de nuestros posicionamientos frente a la enseñanza de las artes", primero deberíamos distinguir cuáles fueron las propuestas presentadas de cara a la enseñanza de las artes, con el fin de comprender los posibles posicionamientos y discursos que pueden estar actuando tras dichas ideas, y luego poder reflexionar así sobre nuestros propios tránsitos, posicionamientos y recorridos frente a la enseñanza artística. Orbeta se apoyó en los cinco enfoques propuestos por Imanol Aguirre (2005) para distinguir las corrientes que circulan dentro de la enseñanza artística. Éstos se distinguen en base al tipo de ideología sobrela cual podría estar fundamentada: el logocentrismo; la expresión; la reconstrucción disciplinar; la cultura visual; y por último, la estética.

Los cinco enfoques aluden a distintas formas sobre cómo se han teorizando las prácticas en la educación artística y, por ende, cómo se han ido conformando como ideologías (Atkinson, s/f). Cada uno de ellos fomenta diversos tipos de prácticas de enseñanza y posiciones discursivas específicas que colocan a los(as) enseñantes, a los(as)docentes, a la categorización del arte y al conocimiento en diversos lugares y jerarquías. Estas posiciones frente a las artes están a merced de los intereses que actúan dentro de las prácticas pedagógicas, así como de la reproducción de numerosos roles e identidades de profesores y estudiantes apoyados en tradiciones previamente definidas. Esto implica unos determinados contenidos, objetivos artísticos y educativos que reflejan los diferentes posicionamientos epistemológicos que se ponen en cuestión. Para advertir cuáles son los posicionamientos implicados en los diferentes enfoques, qué tipo de prácticas de enseñanza artística fomentan y a qué tipo de discursos hacen referencia, revisemos brevemente los cinco enfoques. Aquí el propósito no se centra en cuestionarlos, sino en crear un espacio que permita repensar estos modos de transitar por la enseñanza de las artes y desde éstos reflexionar nuestros propios posicionamientos como profesoras de artes visuales.

La primera perspectiva frente a la enseñanza artística está basada en el enfoque logocéntrico. Ésta se basa en una tradición que nos habla de una práctica docente que toma como referente principal al arte como saber, haciendo alusión al programa logocéntrico de la educación artística. Esta corriente muestra al arte como un saber transmisible, fijo y hermético. El rol del profesor es de un mero transmisor de 
dichos saberes materiales e instrumentales, dejando al estudiante en un segundo plano y sumido bajo una posición de no saber. Es decir, aquí el rol del estudiantado no es protagónico dentro de su propio proceso de aprendizaje ni de la construcción de conocimientos, sino que se remite a ser el receptor de unos saberes entregados por su educador como una única verdad absoluta y fija. Por tanto, "la función de la formación artística consistiría en que el educando adquiera y domine tales preceptos, independientemente de sus intereses o deseos individuales" (Aguirre, 2005, p. 206). En este sentido, al ser una perspectiva recuperada del humanismo renacentista, la función principal del arte es representar.

El segunda perspectiva está basada en el enfoque expresivo de la educación artística. Este enfoque se basa en el arte como expresión y, por ende, la educación artística estaría relacionada con la autoexpresión creativa. Mientras el primer enfoque privilegia la razón, éste fomenta aspectos de tipo sensoriales y emocionales como características formativas. Este discurso es un estilo educativo que se opone al anterior, ya que "no cree que la función principal de la educación artística consista en la transmisión de normas y conocimientos" (Aguirre, 2005, p. 219). En este sentido, las y los docentes buscan desarrollar experiencias estéticas que promuevan una relación libre del estudiante con la creatividad y autoexpresión, por sobre la imitación, la contemplación y la disciplinariedad curricular. Este tipo de experiencias son desarrolladas especialmente por el profesorado de los niveles preescolar y primaria, dónde el educador es quien acompaña el descubrimiento del estudiante y se centra en fomentar los aspectos expresivos. Dichos aspectos expresivos se basan principalmente en lo afectivo o emotivo y no tanto en los aspectos críticos o reflexivos de la realidad que representan.

El tercer enfoque llamado la reconstrucción disciplinar de la educación artística, busca reconstruir y sistematizar esta área de educación desde una perspectiva logocentrista que persigue rescatar el valor cognitivo y no sólo emotivo o psicológico del arte. De esta manera se recupera la lógica maestro-alumno o experto-inexperto como el marco desde donde se genera la enseñanza de las artes. Los contenidos que se transmiten buscan desarrollar la alfabetización visual y se presenta como un modelo de enseñanza iconocéntrico que pone el protagonismo en la imagen. Aquí, las dimensiones de la enseñanza en relación a la representación y comunicación son más relevantes que en otros casos y el discurso teórico que trasciende este enfoque continúa situando al arte como fuente de saber pensado desde su representación y tradición histórica. En relación a esto, la enseñanza de las artes requeriría un docente especializado que pudiese desarrollar en sus estudiantes habilidades como observar y leer imágenes, habilidades de escritura o hablar desde y sobre las imágenes.

Un ejemplo de este enfoque es el proyecto de la educación artística como disciplina (DBAE), el cual surge como oposición a las prácticas de autoexpresión o las prácticas artísticas que no incorporan aspectos de crítica, estética o historia del arte. Se busca desarrollar en los estudiantes un amplio imaginario visual y las obras de 
arte son elementos claves para integrar los contenidos disciplinares, ya que proponen que trabajar con obras de arte permite agudizar la capacidad de comprensión y percepción estética. El rol del profesor sería el de fomentar el cuestionamiento crítico sobre la historia del arte y los aspectos icónicos. Como se desarrolló en apartados anteriores, el currículo artístico chileno ha sido preferentemente desarrollado desde este enfoque.

El cuarto enfoque propone posicionarse desde la educación artística como enseñanza de la cultura visual. Aquí la educación artística es un elemento fundamental para la comprensión de la cultura visual y se busca que los estudiantes aprendan a leer las imágenes desde una relación con éstas.

El enfoque de la cultura visual es más interdisciplinario y toma referentes no sólo del arte sino también de la arquitectura, la historia, la mediatología, la psicología cultural, la antropología, entre otros. Este enfoque propone que la educación artística posibilita desarrollar la identidad de las personas a través de una "relectura que vamos haciendo de nosotros mismos, de nuestras experiencias, nuestras contingencias y nuestro pasado" (Aguirre, 2005, p. 336). En este sentido, el papel de la perspectiva narrativa adquiere mayor relevancia al ser valorada como un método que ayuda a fomentar la interpretación de los relatos de las obras y/o de las imágenes desde el encuentro con las experienciase historias personales. Esta perspectiva implica una forma activa de cuestionar y repensar nuestra realidad desde la imagen y la cultura visual, mientras que docentes y estudiantes van construyendo activamente el conocimiento.

El último enfoque titulado por Aguirre como el arte como experiencia estética contingente, propone ciertas bases para una noción más abierta y pragmática de la educación artística. El arte es concebido como un sistema cultural donde se establece que las experiencias artísticas están relacionadas y conectadas con el resto de experiencias humanas. Desde aquí, este enfoque da prioridad a la experiencia estética como un valor que busca priorizar el carácter performativo de las obras de arte. Es una experiencias que se basa en "enseñar a comprender para transformar" (Aguirre, 2005, p. 298) y donde las obras de arte se sitúan como un medio y herramientas para generar nuevas comprensiones de nosotros mismos. En este sentido, se da gran importancia a la noción de deconstrucción como un elemento que en la enseñanza artística no sólo permite desvelar significados y encontrar valores culturales en los trabajos y creaciones artísticas, sino también, para dar cuenta de las relaciones sociales, políticas, estéticas y culturales que las obras nos señalan y cuestionan. Esto promueve una enseñanza donde los estudiantes pueden apropiarse de estos códigos simbólicos, desarrollar sensibilidad estética y proponer sus propios proyectos identitarios desde sus propias experiencias. Por tanto, el objetivo de la educación artística sería promover una sensibilidad desde la experiencia y creencias personales como espacios para hablar desde nosotros mismos a partir de la experiencia con los otros. 
A partir de estos cinco enfoques y los discursos sobre la enseñanza artística que subyacen en cada uno de éstos, retomamos la invitación inicial de Alejandra Orbeta a pensar sobre nuestros posicionamientos como docentes. Su invitación específica en esos momentos fue "¿en cuál de estos discursos y prácticas de enseñanza nos localizamos?" .Sin embargo, esta pregunta centrada en la elección de un único posicionamiento no representa de la mejor manera el lugar desde el cual nosotras pensamos y entendemos la educación artística y los escenarios que escapan de los relatos hegemónicos que actualmente gobiernan gran parte de la educación tradicional.

Nuestra postura frente a la enseñanza de las artes se basa en entender el proceso de enseñanza y la construcción de conocimientos de una forma dinámica, en constante movimiento, que nunca es lo mismo dos veces y que se construye en relación. Un proceso que considera los diversos roles y discursos que hacen parte de la práctica cotidiana como una multiplicidad de posibilidades dentro de la trayectoria profesional y las relaciones docentes que se constituyen con el estudiantado. Desde aquí preferimos no situarnos desde un único posicionamiento frente a la educación y la enseñanza artística, más bien ser conscientes del desplazamiento que realizamos o hemos vivido entre estos. A partir de nuestras experiencias de vida vamos adoptando y transitando por diversos posicionamientos, y como docentes de arte éstos varían, se movilizan y se apropian de numerosos significados dependiendo del marco en el que la experiencia docente esté inserta, sin olvidar el contexto histórico-político, social y cultural que la determina. En este sentido, la noción de posicionamiento actúa como una posibilidad frente a los diversos desplazamientos que podemos adoptar en el modo de entender la realidad, el proceso de enseñanza y la construcción de conocimientos de una manera reflexiva. Aquí es donde la noción de posicionamiento, que proponemos desde una perspectiva posmoderna, se vincula con la autoría/autorización de nosotras mismas respecto a los diversos recorridos que tomamos frente al qué y el cómo enfrentarnos a la enseñanza de las artes como profesoras/artistas/investigadoras, tomando en cuenta que cada postura o enfoque educativo trae consigo necesariamente unas tradiciones y prácticas de poder frente a los otros (Ellsworth, 2005).

A través de nuestras experiencias educativas nos hemos ido (re)posicionando constantemente como estudiantes de escuela y universitarias, así como profesoras de arte en escuelas y universidades. En cada una de estas experiencias hemos construido una relación con el arte, la enseñanza y el aprendizaje de una manera diferente, y el cómo hemos ido transitando por estas experiencias toma relación con el cómo hemos aprendido las artes durante nuestra vida escolar y universitaria. Estos modos se corresponden con los diferentes enfoques y tradiciones trasmitidas en nuestra formación, bajo unos discursos concretos que constituyen a una formación artística y pedagógica específica. Tomando en cuenta el pasado y las tradiciones que acarreamos como docentes, asumimos esta cuestión como una posibilidad para pensar desde aquí nuestras trayectorias y diversos posicionamientos como 
profesoras de artes visuales, artistas e investigadoras en formación. Junto con esto, no podemos olvidar el poder que ejercemos sobre nuestros(as) propios(as) estudiantes frente a la(s) posición(es) que adoptan frente a la enseñanza de las artes y el cómo van conformando su conocimiento de la realidad a través de lo artístico. Tal como propone la autora Elizabeth Ellsworth (2005), hemos de estar atentas al papel que jugamos como docentes dentro del proceso educativo y las relaciones de poder que se ponen en acción dentro de éste.

En este sentido, como propone Efland et al. (2003), los y las profesoras de arte que siguen pensamientos posmodernos desarrollan sus prácticas valorando su entorno ideológico, el de sus estudiantes y el de la comunidad educativa donde participan, intentando orientar a sus estudiantes "hacia una comprensión completa del impacto de la vida social sobre la creación de conocimientos y la construcción de la propia identidad." (Efland et al, 2003, p. 81). Si enseñar exige una reflexión crítica sobre la práctica (Freire, 2002), proponemos que estos cinco enfoques propuestos por Aguirre (2005), sean espacios por donde los(as) profesores de arte puedan transitar reflexivamente para hacer de sus enseñanzas espacios de libertad política hacia ellos(as) y sus estudiantes. Desde aquí que ser conscientes de la variedad de enfoques, niveles, cambios e influencias existentes en la educación artística se vuelve necesario y prioritario para que nuestras prácticas se transformen en espacios de subjetividad política y que nos permitan construir nuestro saber y experiencia docente cuestionando las ficciones y herencias tradicionales que subyacen en la enseñanza de las artes.

\section{Reflexiones finales}

La noción de posicionalidad en las prácticas educativas no sólo atañe a la educación de las artes, sino también a los diversos posicionamientos que se ponen en juego dentro de las relaciones entre docentes/estudiantes y docentes/docentes. Por tanto, pensar sobre una o varias posiciones como las señaladas en este artículo, o bien transitar entre ellas desde un sentido crítico y no excluyente, nos parece una cuestión fundamental. Ya lo señalaba Freire (2002, p. 39) cuando nos recordaba que "la práctica docente crítica, implícita en el pensar acertadamente, encierra el movimiento dinámico dialéctico entre el hacer y el pensar sobre el hacer". A partir de aquí nos propone que uno de los saberes fundamentales como docentes está centrado en la reflexión crítica sobre la práctica que desarrollamos a diario dentro del proceso de enseñanza. Este pensar, además de orientar nuestro quehacer cotidiano, debe situarse, o bien comprenderse, como un saber fundamental tanto dentro de la formación inicial como a lo largo del desarrollo profesional permanente ya que puede ayudarnos a abrirnos a otros territorios desde donde concebir nuestras prácticas.

Es por esto que para nosotras es esencial pensarnos desde una posición en la cual no exista una manera única y fija de ser, estar y hacer como docentes y, por tanto, 
de constituir relaciones pedagógicas y generar conocimientos. Éstas deben estar pensadas desde la movilidad, el tránsito constante y la capacidad de desplazarnos en múltiples direcciones y bajo diversos significados, entendiendo que es posible aprender desde un lugar de no saber (Atkinson, 2011). Desde aquí nuestra tarea cómo docentes no se establece bajo la suposición hegemónica de la transferencia de conocimientos, sino en crear y posibilitar espacios que permitan a los estudiantes a desarrollarse y resituarse en el centro de la acción educativa, posibilitando de este modo, que ellos y ellas se construyan de manera autónoma a través de la comprensión de su propia experiencia. Esta colocación a su vez nos interroga frente a nuestro accionar como profesoras de arte, posicionándonos desde el territorio mismo de la educación, es decir, desde una posición constante de no saber (Contreras y Pérez de Lara, 2010; Hernández, 2011). De esta manera la tarea docente es entendida como una experiencia personal que nunca es la misma, que no se puede controlar, que es subjetiva y desestabilizante, pues depende siempre de un encuentro con otras personas, que necesita alimentarse e inspirarse en otras maneras de conocer, de construir conocimientos, de preguntarse y de entender la realidad (Carrasco, 2015).

Con todo, el acto de pensar sobre nuestras prácticas docentesdesde lo qué significa aprender a ser profesoras de arte en el mundo actual y las múltiples decisiones que agencian en este proceso, nos puede ayudar a mejorar las prácticas de hoy y del mañana y, a la vez, afrontar los crecientes retos que aparecen desde los relatos hegemónicos que gobiernan gran parte de la educación tradicional chilena bajo un estatus fijo desde el cual el profesor ha de cumplir el rol de especialista dentro las diversas disciplinas artísticas. Todo ello convive diariamente con una sociedad profundamente transformada mediante la prevalencia de la tecnología y los numerosos modos de relacionarnos - física y virtualmente- desde entendimientos que consideran la presencia de fuerzas humanas, no humanas y materiales. Por tanto, si enseñar no se basa en la transferencia de conocimientos sino en generar posibilidades para que estos otros modos de entender la enseñanza, el aprendizaje y la realidad sean construidos en relación dentro de estos nuevos escenarios, nuestras reflexiones finales las proponemos como espacios de diálogo para seguir pensando la enseñanza artística y así abrirnos a las múltiples posibilidades que nos llevan a pensar la educación más allá de lo establecido dentro de nuestros contextos más locales y/o internacionales.

\section{Referencias bibliográficas}

Aguirre, I. (2005). Teorías y prácticas en educación artística. Ensayo para una revisión pragmatista de la experiencia estética en educación. Barcelona: Octaedro.

Atkinson, D. (s/f). Without Criteria: Art and Learning and the Adventure of Pedagogy. Artículo por publicar en The international journal of art \& design education.

- (2011). Art, Equality and Learning: Pedagogies Against the State. Rotterdam: Sense Publishers 
CARRASCO \& GARCÍA-HUIDOBRO/ Repensando nuestros posicionamientos como profesoras de arte dentro de un escenario de cambios

Badiou, A. (2005). Being and Event. London \& New York: Continuum.

Bauman, Z. (2007). Miedo líquido. La sociedad contemporánea y sus temores. Barcelona: Paidós.

Benavides, F., y Leiva, P. (2002). Desafíos para la educación artística en el contexto de la reforma curricular chilena. Pensamiento educativo, (30), 99-120.

Blackman, L., Cromby, J., Hook, D., Papadopoulos, D., y Walkerdine, V. (2008). Creating subjectivities. Subjectivity, (22), 1-27. doi: 10.1057/sub.2008.8

Carrasco, S. (2015). Entrar en relación y aprender juntos a partir de la descolonización de los cuerpos. REIRE, Revista d'Innovació i Recerca en Educació, 8 (2), 80-93. doi: $10.1344 /$ reire2015.8.2825

Carrasco, S., García-Huidobro, R. (2016a). La cultura visual y los pequeños relatos como desafíos para la educación artística. REIRE, Revista d'Innovació i Recerca en Educació, 9 (1), 1-10.

- (2016b). Educación artística. Construyendo desde la marginalidad y la precariedad. Revista Invisibilidades, (9), 105-112.

CNCA (2013). Completando el modelo educativo. 12 prácticas de educación artística en Chile. Santiago: Consejo Nacional de Cultura y Artes.

Davies, B., y Harré, R. (1999). Positioning and personhood. En R. Harré, y L. Van Lagenhove (Eds.), Positioning theory: Moral contexts of intentional action (pp. 3252). Malden, MA: Blackwell.

Davies, B. y Harré, R. (2007). Posicionamiento: La producción discursiva de la identidad. (Traducción de César Cisnero). Athenea Digital, (12), 242-259. Recuperado de http://psicologiasocial.uab.es/athenea/index.php/atheneaDigital/ article/view/f.

Díaz, F. (2014). Integración educación artística en curriculum escolar. Desafíos del programa de gobierno actual en Chile. Congreso Iberoamericano de Ciencia, Tecnología, Innovación y Educación, Buenos Aires.

Efland, A., Freedman, K., y Stuhr, P. (2003). La educación en el arte posmoderno. Barcelona: Paidós.

Eisner, E. (1998). The Role of Discipline-Based Art Education in America's Schools". Los Angeles: The Getty Center for Education in Arts-

Freire, P (2002). Pedagogía de la autonomía. Saberes necesarios para la práctica educativa. Buenos Aires: Siglo Veintiuno.

Harris, R. (1982). The language makers. London: Duckworth. 
Hernández, F. (2011). Investigar con los jóvenes para dar cuenta de sus relaciones con el saber. En F. Hernández (Coord.), ¿Qué nos cuentan los jóvenes? Narraciones biográficas sobre las relaciones de los jóvenes con el saber en la escuela secundaria (pp. 7-13). Barcelona: Esbrina Recerca.

Padilla, A. (2001). El Pensamiento Didáctico en la Educación Artística: reto en la formación de profesores. Facultad de Educación, Pontificia Universidad Católica de Chile.

Smith, P (1988). Diserning de Subjetc. Minneapolis: University of Minnesota Press. 